\title{
Exploration of Translation Teaching under Constructivism Theory Rong Ma
}

Ningxia Vocational Technical College of Industry and Commerce, Yinchuan, 750021, China

\author{
Keywords: Constructivism theory, Translation teaching, English education
}

\begin{abstract}
Constructivism theory points out that learning and studying process is a process where learners consciously construct mental activities in the learning process. In teaching practice, constructivism theory stresses students should serve as the center of teaching activities and focuses on interactive teaching evaluation between teaching process and students. Hence, this theory plays a great role in teaching reform and teaching efficiency promotion in Chinese modern society. This paper starts from analysis of constructivism theory, explores translation teaching reform and innovation modes under constructivism theory and hopes to further improve translation teaching quality and cultivate excellent translation talents.
\end{abstract}

\section{Introduction}

As worldwide economy integration trend enhances and the study on translation teaching further develops, an increasing number of other thoughts and theories are introduced in translation teaching research. These thoughts and theories generate very important effects on modernization development of translation teaching study. Since the middle $20^{\text {th }}$ century, all kinds of correlation theories are applied in translation studies. Hence, very prosperous competitions appear. Constructivism theory formally appeared in 1970s. It is a significant branch of cognitive theory and another breakthrough after important behaviourism in education learning theory develops and evolves to cognitivism. Constructivism theory overall explores learning rules from a brand-new perspective and creatively sets forth common learning process with new theories. After it is practically applied in educational practice, important reform of national education is promoted. It generates very significant influence on modern development of education.

\section{Basic education concept in constructivism theory}

Through observing and studying cognitive process, constructivism education research scholars Piaget et al. point out that the process where human beings learn knowledge and cognize the society is a dual-construction process where the awareness of the subject and object maintains dynamic balance development under the influence of social education thought. Under such precondition, radical constructivism represented by Glasersfeld considers knowledge accumulation process is not a process where learners simply passively receive, but it is constructed consciously and actively through application of the subject to be cognized. Besides, such construction process can be achieved through interactions between new and old knowledge systems ${ }^{[1]}$. Constructivism thought with certain social nature confirmed under the influence of Vygotsky considers cooperation among each learner may be regarded as the center of education practice activity through jointly constructing a community. Social and cultural cognitive theory which is also gained under the influence of Vygotsky explicitly points out that, construction not merely represents acquisition of new knowledge through handling and reediting existing old knowledge system, but also should recombine old knowledge system while injecting new knowledge.

The teaching mode which is derived from application of constructivism in teaching practice mainly regards students as the center of teaching activities. Teachers undertake the heavy responsibility of organizer and helper in the whole teaching activities. They mobilize students' learning initiative and enthusiasm through applying all kinds of teaching situations and discussion in classroom teaching so as to reach the construction purpose of improving teaching effects. 
Constructivism mainly emphasizes students' subject position and teachers' teaching guidance role in classroom teaching practice. Learners deepen understanding and mastery of relevant knowledge in learning process through cooperating with others or individual exploration. Teachers are guide and helper in the process where students construct new knowledge system, rather than knowledge infuser in traditional teaching thought. Classroom teaching process is actually a process where teachers help and guide students to fuse and digest new and old knowledge systems and also the process of guiding and helping students to consciously explore and actively construct new knowledge system by regarding original learning experience as the construction point ${ }^{[2]}$. In one word, teachers who act as the guide in teaching activities should transfer new knowledge exploration and construction to students, guide and help them to gradually cultivate the habit of constructing new knowledge system in the learning process, and train their independent learning ability in growth so as to lay a solid foundation for their future development.

\section{Internal relation between constructivism theory and Chinese translation teaching}

Constructivism theory is an education learning theory which has risen and rapidly received attention from the whole world in western developed countries in recent years. It is also an important branch of cognitive theory. As a novel education learning thought, constructivism theory indicates the essence of learning activities is the whole process where students construct inner mental representations. Learners' acquisition of new knowledge system and formation of related learning skills cannot be completed through teachers' infusion teaching style. Learners utilize their original knowledge system and experience as well as necessary teaching materials to acquire these through construction at meaning level with the help of other classmates, teachers and even strangers under specific social and cultural background.

In translation teaching class guided by constructivism theory, students are no longer passive receivers of teaching activities and translation tools, but gradually become conscientious and active learners $^{[3]}$. In this process, students are able to combine their knowledge reserve and life experience to participate in translation teaching activities, discover learning joys through teaching practice, discussion and teamwork, then deepen understanding of relevant knowledge points in real situation training and finally achieve cognition and systematic construction of translation knowledge.

\section{Problems existing in Chinese traditional translation teaching}

\section{Teaching thought and teaching method lag behind relatively}

Over the years, education researchers in Chinese translation industry firmly believe translation work is to transform relevant character information in the source text to the information of target language. Translation work is only limited to understanding and organizing words. For a long term, under guidance of such old-fashioned translation education concept, Chinese translation teaching places key teaching points on training students' listening, speaking, reading and writing abilities. Students' instant translation ability training is ignored, and the teaching effect is poor. Although Chinese translation teaching has started to receive attention from various universities in recent years, the students of non-language major can only receive plain translation education in practice. Even the students of language major can only receive professional skill training for 1-2 semesters in senior grades. In teaching practice of college translation courses, teachers implement translation education by deeming them as the center and actually control the whole teaching process from material selection to teaching evaluation. They stress theory and ignore practice. Students can only passively receive translation teaching knowledge in classroom teaching, but cannot take active part in classroom activities. This is adverse to cultivating independent translation ability.

\section{Course setting lacks scientificity and teaching materials lag behind relatively}

For the students of non-language major, elective course teaching mode is often applied. The course contents are relatively simple and the theories lack systematicness, let alone translation skills and practical teaching. This imposes certain adverse impacts in improving teaching effect. Meanwhile, 
college education management personnel pay insufficient attention to translation teaching. The teaching materials are obsolete teaching materials which are disconnected with current social reality and have poor practicability ${ }^{[4]}$. Generally, teaching materials for Chinese translation teaching have certain generality, i.e. from translation of single words to sentence translation and then from sentence translation to paragraph translation and the whole article translation. Teaching material preparation thought has a uniform mode. The examples are simple and have strong systematicness, which results in dull and boring classroom teaching to some extent and has negative effects on students' study.

\section{Translation teaching reform and innovation under guidance of constructivism thought}

\section{Change teaching concept}

Constructivism teaching thought indicates learning process is a simple process in which teachers infuse knowledge to students, but a process where s student constructs knowledge system under the guidance and help of the teacher. As for Chinese translation teaching, translation teaching is a course with strong practicalness. Simply speaking, students' acquisition of translation ability in learning proves is to accumulate personal translation experience in learning process, select relatively relational translation thought in combination of their own features and get rid of the learning thought refined by teacher or others according to their experience. Chinese traditional translation teaching generally follows the teaching mode of first practicing and then teaching, which may easily result in separated teaching, learning and practicing in teaching development process. In this way, students disconnect with theoretical knowledge mastery and practical ability promotion in learning process. Even if they can deeply understand all knowledge in teaching practice, they generally lack the ability to solve practical problems. Thus, this is adverse to students' all-round development. Opposite to traditional teaching thought, constructivism teaching thought advocates to construct and generate new knowledge on the basis of existing knowledge system and proposes to gradually boost various abilities in practical learning ${ }^{[5]}$. Therefore, constructivism teaching thought should be introduced in translation teaching, and teachers should change teaching thought under theoretical guidance, regard students as the center of teaching practice and adopt certain teaching methods and measures to motivate students' learning initiative and enthusiasm. Besides, teachers should clearly realize their primary task is to offer corresponding learning practice opportunities for students, cultivate students to gradually develop self-exploration, self-discovery and problem-solving ability and deepen understanding and mastery of translation teaching theories in situational translation process on the basis of imparting a large number of basic skills. In this way, teachers may explain and deeply analyze translation theory and difficult points in teaching again after students finish translation practice, really erect an important bridge between scientific education thought and students' knowledge structure system, arouse students to improve knowledge application ability through consciously and actively thinking and internalizing explicit knowledge.

\section{Create translation teaching skill training mode}

In Chinese translation teaching, traditional educational thought pays more attention to teaching results. Teachers generally comment students simply after students finish tasks and then directly explain correct translation answers to students. Although such mode contributes to simplifying teaching process to some extent and reduces errors, teacher-led training mode ignores students' individual thinking, restricts stimulation of students' potentials and hinders improvement of students' comprehensive quality. Constructivism teaching theory explicitly indicates in practical application that, teachers and students experience teaching and learning process in classroom teaching is actually the process of cultivating students to discover problems, raise problems, analyze problems and solve problems. To guarantee teaching quality in this process, it is required to focus on training students' self-study exploration ability. The application of constructivism teaching thought in translation teaching shows the attention to cultivating students' translation ability and creates advantageous conditions for students to learn skills, experience learning skills and accumulate experience in translation skill training. 


\section{Create translation practice situation for classroom teaching}

Constructivism teaching thought indicates that if learners want to really activate and construct the knowledge in learning process, they must go deep into real situations to feel specific application of related knowledge. In other words, they should finish study through directly acquiring practical experience. In current translation teaching, traditional teaching mode cannot provide learners with real situation training opportunity and increases the difficulty in constructing translation knowledge system at meaning construction level, so teachers should create the conditions for students to receive tasks, and implement translation practice, organize students to experience translation practice.

\section{Reform and create teaching evaluation mode}

In Chinese traditional translation teaching thought, teachers are generally based on "standard answers" during explaining translation problems, analyze and comment students' translation after finishing teaching tasks, try to consolidate students' knowledge system in the commenting process and impart their own experience to students. But, such teaching mode restricts students; thinking development to some extent, limits activation and further development of students' translation potentials, even easily triggers students to resist translation study and affects learning effect. Constructivism teaching theory pays more attention to students' enthusiasm and initiative for participating in translation teaching activities and hopes to make students construct personal knowledge system under teachers; guidance and help. Interactive teaching evaluation under the influence of constructivism theory exactly reflects interactive teaching thought and differs with traditional teachers' personal comment evaluation mode. Such scientific teaching evaluation mode pays more attention to interactions between teachers and students and among students. It reforms and creates Chinese traditional teaching evaluation method and has certain progress.

\section{Conclusion}

Constructivism theory opens up a new situation of Chinese translation teaching and offers more advanced theoretical direction for implementation of modern teaching reform and new development direction for teaching mode innovation and learning mode exploration. Hence, it positively promotes foreign language teaching in China. During applying constructivism in translation teaching practice, teachers should deem students as the subjects of teaching activities under the guidance of educational theory, actively listen to students; opinions on teaching mode innovation, continuously improve teaching methods and boost teaching effectiveness.

\section{References}

[1] Liu Dong, Discussion on problems in college English translation and new teaching mode. New Curriculum Research (Higher Education), 2011(3):66-68.

[2] Huang Li, Translation teaching under constructivism theory. Shanghai Journal of Translators, 2011(3):69-70.

[3] Zhou Ling, College English translation teaching under guidance of constructivism theory. Science and Technology of West China, 2015(4):91-91,93.

[4] Zhao Dan, College English translation teaching research and practice under guidance of constructivism theory. Intelligence, 2014(18):74-74.

[5] Liu Hong, Discussion on college English translation teaching strategy from constructivism perspective. English Square (periodical appearing in the last ten days of a month), 2014(12):27-29. 